\title{
Affine arbitrage-free yield net models with application to the euro debt crisis
}

\author{
Zhiwu Hong ${ }^{a, b *}$ Linlin $\mathrm{Niu}^{b, c \dagger}$ Chen Zhang ${ }^{d \ddagger}$ \\ ${ }^{a}$ Business School, China University of Political Science and Law \\ ${ }^{b}$ Wang Yanan Institute for Studies in Economics (WISE), Xiamen University \\ ${ }^{c}$ MOE Key Laboratory of Econometrics, School of Economics, Xiamen University \\ ${ }^{d}$ School of Economics, Xiamen University
}

\begin{abstract}
We develop a parsimonious class of affine arbitrage-free yield net models for consistent bond pricing across maturities and issuers of different risk levels. Containing a core curve and multiple peripheral curves, the yield net is spanned by three layers of factors: base factors spanning all curves, and common and individual spread factors. Under the arbitrage-free assumption, we prove a parsimonious solution to the risk-neutral process that guarantees joint identification of parameters and latent states. By using a Bayesian estimation method with a marginal Metropolis-Hastings algorithm and specification tests based on MCMC output, we apply the model to weekly treasury yields of Germany, Italy, Spain, and Greece from 2009 to 2016. The results show that the extracted common credit risk is a level factor in spread, and market liquidity risk is a slope factor. Further, the net structure helps reconstruct the Greek yield curve even with only its 10-year yield available throughout the sample.

Keywords: Term structure models, European debt crisis, liquidity risk, sovereign credit risk, Nelson-Siegel factors
\end{abstract}

JEL Classification: C33, E43, G15

*Zhiwu Hong, Business School, China University of Political Science and Law. E-mail: hzw1888@126.com.

${ }^{\dagger}$ Corresponding author: Linlin Niu, Rm A306, Economics Building, Xiamen University, Xiamen, 361005, Fujian, China. E-mail: llniu@xmu.edu.cn. Phone: +86-592-2182839. Fax: +86-592-2187708.

${ }^{\ddagger}$ Chen Zhang, School of Economics, Xiamen University. E-mail: 18959203592@126.com. 


\section{Introduction}

At one time, debt crises were a recurring problem primarily in emerging markets. After the 2008 financial crisis originated in the U.S., they became a widespread phenomenon in the developed world. In the course of a debt crisis, investors and policy makers face the challenge of understanding changing sources of risks and varying mechanisms of risk transmission. In an increasingly globalized financial market, risk analysis and portfolio management call for modeling tools with a theoretical foundation for high dimensional assets. Policy makers need to understand the complexity of risk interaction and evaluate the effectiveness of policy measures in curbing risks, both locally and internationally. This paper develops a parsimonious affine arbitrage-free modeling framework for bond yields across maturities and issuers of different risk levels, i.e., a yield net, with a three-layer factor structure to disentangle sources of risks.

Taking the euro debt problem as an example, Figure 1 provides a plot of the 10-year sovereign bond yields of Germany (GE), Italy (IT), Spain (ES), Ireland (IE), and Portugal (PT) from 2000 to 2016. The dynamics of sovereign yields reflect structural changes in the European currency union due to the different economic fundamentals of member countries. Before the crisis, government bond yields across the euro member countries enjoyed a stable convergence period during which only a tiny margin of liquidity premium remained in yield spreads with respect to the benchmark German Bunds (Favero et al., 2010). During this period, investors valued these sovereign bonds as a homogeneous group; therefore, it suffices to model the German yield curve in order to describe the co-movement of the peripheral yields. However, starting in 2008, bond yields began to diverge wildly between core countries, such as Germany, and peripheral countries, such as Greece, Italy, Ireland, Portugal, and Spain (GIIPS). The movements of 10-year yield spreads of GIIPS on German Bunds shared a trend, but their magnitudes and the timing of local peaks and troughs were distinct, indicating that both euro area common risks and country-specific risks were at work.

Figure 2 plots the sovereign yield curves of Germany and four of the GIIPS countries (excluding Greek yields, which shot up far above the rest) at two stages, showing an initial homogeneous group turning into a crisis mode with diverse levels and shapes, implying varying combinations of risks. The dynamic features of these yields along different dimensions reflect market expectations on the future of the euro and risky paths of member countries. In this context, effectively utilizing the information both along the term dimension and risk dimension - a net-like struc- 
ture - is key to understanding bond pricing and risk transmission in the euro area, which is of crucial importance for bond investment, risk management, economic monitoring, and policy intervention.

[Figure 1. 10-year government bond yields of Germany, Italy, Spain, Ireland, and Portugal]

[Figure 2. A euro yield net at two dates: 2009/10/30 vs. 2012/07/27]

There are empirical and theoretical challenges to modeling a high-dimensional yield net to achieve both dimension reduction and consistent pricing. On dimension reduction, factor analysis in reduced form is popular, either along the maturity dimension for a single curve or the risk dimension given the maturity of different issuers. In the studies on sovereign yields across countries, the focus is often on the co-movement in yield spreads of a certain maturity, which omits information from the core yield curve and other maturities. The factors extracted from a reduced-form model may capture the risk structure across countries, at the cost of consistent bond pricing along the maturity dimension. The affine arbitrage-free term structure models (ATSMs) provide a consistent pricing framework for single yield curves. However, in a yield net with closely related yields across issuers, modeling each yield curve with an ATSM of its own factors is neither efficient nor parsimonious, and it is also silent about the risk structure across yields of different issuers. Simply expanding the no-arbitrage single curve model to accommodate multiple curves by proportionately increasing the number of state factors will soon incur the curse of dimensionality. Consequently, the joint modeling of yields of multiple issuers and maturities under the no-arbitrage restrictions has not been sufficiently investigated with widely accessible modeling tools, and applications are very much constrained.

This paper contributes to the literature by developing a parsimonious arbitrage-free yield net modeling framework, that is, a joint framework of a core curve and multiple peripheral curves under the no-arbitrage restrictions. At a given time, the net extends in the dimensions of both maturities and risks, which are bound together by three underlying layers of factors. The factors in turn determine the core yield curve, the co-movement of yield spreads, and the idiosyncratic component of each peripheral curve. We prove that, under the no-arbitrage condition, the spanning structure of factors implies highly parsimonious parameterizations in the risk-neutral process, which then helps with identification of parameters and latent states. In the empirical application, we illustrate the analysis with a model of four yield curves - the 
sovereign yields of Germany as the core, and those of Italy, Spain, and Greece as the periphery. We identify common factors and idiosyncratic factors, price bonds consistently across maturities and sovereign issuers, and quantify the dynamic interaction of risks and their impacts across countries in a unified framework.

Moreover, this paper presents a thorough and rigorous empirical study based on advanced tools of Bayesian methods to tackle the estimation challenge in such a high-dimensional and nonlinear asset pricing model with latent states. In such models, the classical method of maximum likelihood estimation suffers from the reliability problem of finding globally optimal parameter values and computing standard errors for further inference; the typical Bayesian method of single-move Gibbs sampler suffers from the non-convergence problem due to the extremely slow mixing when the latent states and non-linearly involved parameters are highly correlated. We show that a marginal Metropolis-Hastings algorithm with multivariate proposals can be applied to overcome the estimation challenge in such a high-dimensional yield net setting.

Although this paper focuses on European sovereign bond pricing under the backdrop of the euro debt crisis, the framework can be generalized to study multiple yield curves featuring a "core-periphery" relationship in widely applicable cases. Moreover, the model is flexible enough to accommodate such cases when a certain issuer does not have yield observations from a full spectrum of maturities. In the application of this paper, for example, Greece only has a 10-year yield available throughout the whole sample period. Since other yield curves in the net already provide rich information on common factors of the first two layers, we can still identify the Greek risk factor, study its interaction with other factors and sovereign yields, and reconstruct an implied yield curve for Greece.

The rest of the paper is arranged as follows. Section 2 links our method and perspective with the literature on the euro debt crisis and yield curve modeling. Section 3 establishes the modeling framework and discusses model specifications. Section 4 discusses the Bayesian Markov chain Monte Carlo (MCMC) sampling procedure and the methodology for the specification tests. Section 5 describes data and construction of the market liquidity risk factor used in the empirical analysis. Section 6 is devoted to an empirical application to modeling European sovereign yields during the euro debt crisis. Section 7 concludes. 


\section{Literature Review}

The movement of a yield net is driven by the underlying risk factors. To model the co-movement of yields efficiently, dimension reduction requires classification of factors, and consistent pricing requires imposing theoretical restrictions. With a focus on modeling the European sovereign yields during the euro debt crisis, we first review the various related studies on factor structure and dynamics; then we review the methodology on modeling interest rate term structure and related research on jointly modeling multiple yield curves.

\subsection{Factor structure and dynamics}

Concerning bond yields of diverse risks denoted in the same currency, such as in the euro debt problem, many macro-finance studies highlight various macroeconomic fundamentals that drive up yield spreads on a core yield curve, for example, the yield curve of German Bunds. Favero and Missale (2012) find that the default risk, which is related to fiscal fundamentals, is the main driver of yield spreads. Following Joslin et al. (2014), Dewachter et al. (2015) show that the euro area sovereign yield spreads can be explained by country-specific economic factors, euro area economic fundamentals, and international influence, and that the economic fundamentals are the dominant drivers.

At the same time, the effects of fundamental factors can be transformed to bond default risk and liquidity risk, which have to be priced into yield spreads in order to compensate investors for holding these bonds with respect to risk-free benchmark bonds. The major component of yield spreads typically varies between systematic credit risk and market liquidity risk (Beber et al., 2009; Favero et al., 2010; Monfort and Renne, 2014), and they are dynamically intertwined during a crisis period (Calice et al., 2013; Pelizzon et al., 2016). An identification strategy is necessary to separate these two components, which is of importance to risk management as well as policy evaluation. Longstaff (2004), De Santis (2014), Garcia and Gimeno (2014), and Schwarz (2019) find significant evidence of liquidity premia in spreads. They use yield spreads between sovereign bonds and bonds issued by government sponsored agencies enjoying sovereign credit as a proxy of liquidity risk factor. In our modeling framework, we use a similar proxy for market liquidity risk and consider flexibility of accommodating latent factors as well as observable factors to separate different types of risks.

In terms of risk dynamics, co-movements are common in yields and yield spreads across coun- 
tries, indicating that international risk factors and country-specific factors coexist. Monfort and Renne (2014) find that two principal components explain up to $90 \%$ of variations of sovereign yield differentials across the euro area. Favero (2013) models yield spreads in the euro area with three factors: a local factor, a common factor of risk appetite, and a third common factor reflecting expectations of exchange rate devaluation. To capture changes in the pricing mechanism of bond yields during the crisis, Adam and Lo Duca (2017) use a five-factor model with time-varying loadings and stochastic volatility to study the dynamics and drivers of sovereign bond yields in euro area countries. Using CDS data, Aït-Sahalia et al. (2014) also find evidence of self- and cross-excitation of shocks, which are relevant for pricing yield spreads.

Based on the above evidence and modeling practice, without losing generality, we group the underlying factors into three layers in our framework of "core-periphery" yield curves:

1) the core yield factors, fully spanning the benchmark yield curve as the common basis for all curves;

2) the common spread factors, including common credit risk and market liquidity risk, spanning all peripheral spreads;

3) the specific risk factors, each spanning the yield spreads of a relevant peripheral curve.

Given the set of three-layer factors, our model is capable of examining the risk interaction and transmission via various mechanisms in a unified framework under arbitrage-free restrictions. The analysis and results will complement existing studies on the effects of common risks, contagion and spillover effects between sovereign issuers, many of which rely on reduced-form modeling of vector autoregression (VAR) on yields or yield spreads(Antonakakis and Vergos, 2013; Ehrmann and Fratzscher, 2017), or on spread regressions with observable control variables (Beetsma et al., 2013; Giordano et al., 2013).

\subsection{Term structure of yields}

Methodologically, most analysis on the euro debt crisis have been carried out using reduced-form models without theoretical restrictions on the consistency of bond pricing. Although reducedform models provide considerable robustness and flexibility for identifying the main sources of risks and the co-movement patterns of yield spreads, the no-arbitrage condition is indispensable 
to consistently pricing bonds along maturities for a single yield curve and across countries for multiple yield curves that are closely linked by common factors.

There is a vast literature on yield curve modeling under the no-arbitrage condition, starting from Vasicek (1977) and Cox et al. (1985). While early work assumes that government bond yields are default-free, Duffie and Singleton (1999) proposes a sovereign yield curve model that is subject to default risk. The macro-finance approach of the no-arbitrage yield curve model with macro fundamentals was pioneered by Ang and Piazzesi (2003).

In the research on the European debt crisis, a number of papers model single yield curves with macro fundamentals and study their risk pricing; these include Bi and Leeper (2010) and Bi (2012). However, the single curve modeling approach omits useful information from yields of other members that share a common basis with the German yields and common spread factors driving all yield spreads. Some papers study a set of two yield curves to explore the link between them, such as Dewachter et al. (2015) on each of the five peripheral yield curves together with the benchmark German curve. This coupling approach helps examine the effects of different macro factors on the yield spreads, but the two-curve model lacks the ability to distinguish country-specific risks from common risks in the euro area, or to study spillover effects among member countries.

Among research on jointly modeling multiple yield curves, Monfort and Renne (2014) impose the no-arbitrage condition and extract the individual default intensity of a peripheral yield curve conditional on an observable proxy of the market liquidity factor. However, without disentangling country-specific default risk from common credit risk in the euro area, it is unclear how these different sources of risks interact with each other in building the yield spreads. Ang and Longstaff (2013) model multiple CDS spread curves. They decompose systematic and sovereign-specific credit shocks in a no-arbitrage multivariate credit framework based on Duffie and Singleton (2012) and find that systematic risk plays a larger role in the Eurozone than in the U.S.. However, credit risk and liquidity risk are not separately identified and the interaction between credit risks and the benchmark yield curve is left out in their framework.

In contrast to Ang and Longstaff (2013), our paper models yield curves directly, enabling simultaneous investigation of the interaction between periphery risks and benchmark yield factors. In our no-arbitrage yield net model of $1+M(M \geq 2)$ yield curves with three-layer states, factors and parameters can be estimated jointly. We prove that the factor structure across maturities 
and issuers leads to parsimony and helps identify parameters and latent factors. For further parsimony in modeling the core yield factors of the German Bunds, we assume Nelson-Siegel (NS) interpolations. The arbitrage-free NS (AFNS) model was first developed by Christensen et al. (2011) to combine the advantages of parsimony and flexibility of the traditional reduced-form NS models (Nelson and Siegel, 1987; Diebold and Li, 2006) and the theoretical consistency of arbitrage-free models. Li et al. (2011) introduce additional factors to span the space of yields and develop an arbitrage-free extended Nelson-Siegel (AFENS) framework. Christensen et al. (2014) use a 6-factor extended AFNS model to describe the joint dynamics of six US yield curves with the Treasury yield curve as the core curve, where a second set of level and slope factors is employed to model the common spread factors of peripheral bond yields and only a specific factor is necessary to model the behavior of the LIBOR rate. In comparison, our approach enables economic interpretation on the spread factors.

Nesting AFNS and AFENS models with the three-layer factors specified for a core-periphery type yield net, we show that this framework is a more general, yet parsimonious, setting to examine the joint dynamics of high-dimensional yields under consistent pricing restrictions. This structure is not only suitable for the relationship of sovereign yield curves in the euro area, but also applicable to the relationship between sovereign and sub-sovereign yield curves within a country where bonds are issued both by a central government and multiple local governments, or between a treasury yield curve and corporate yield curves denoted in the same currency. To this end, the 6-factor extended AFNS model of Christensen et al. (2014) can be nested in our framework as a special case without specific factors for each peripheral curve due to the more homogeneous risk sources in the US domestic market.

By applying this framework to the modeling of European sovereign yields with diverse risks during the euro debt crisis, we demonstrate the robustness of factor extraction with economic underpinnings, rich implications on the risk dynamics across countries, and the power of the net to provide pricing information for some of the yield curves with sparse observations.

\section{An arbitrage-free yield net model with three layers of factors}

In this section, we build a yield net model, that is, a joint model of $1+M$ yield curves with a core-periphery structure, where the core curve is assumed to be default free and the other curves 
are subject to different degrees of risks. In the context of euro area sovereign yields, the lower bound of the net is the benchmark core curve of German yields, above which are $M(\geq 2)$ yield curves of the peripheral countries.

\subsection{Model classification}

For ease of elaborating the model setting, we denote a specific affine arbitrage-free yield net (AN) model as

$$
A N^{1+M}\left(k_{1}, k_{2}, k_{3}\right)
$$

where

- $M$ is the number of peripheral yield curves;

- $k_{1}$ is the number of base factors spanning the core yield curve, and $k_{1}=3$ when the AFNS model is chosen for the block of the core curve;

- $k_{2}$ is the number of common risk factors spanning peripheral yield spreads, $k_{2}=1$ or 2 in a typical situation;

- $k_{3}$ is the number of specific factors. In modeling euro sovereign yields with diverging country specific risks, we choose $k_{3}=M$, such that each specific factor spans a corresponding peripheral curve. Alternative cases can be considered. For example, the model of Christensen et al. (2014) can be regarded as a special case with $k_{3}=1$ when the risk sources of peripheral curves are highly homogeneous, as in the case of a domestic bond market.

\subsection{The term structure given factors for each issuer}

The yields of the core curve are marked by an asterisk, $*$, and those of other issuers are denoted with a number $i(i=1, \cdots, M)$. The benchmark yields are determined by the three NS factors $X_{t}^{N S}=\left[L_{t}, S_{t}, C_{t}\right]^{\prime}$, which serve as a common basis shared by all yields. The yield spreads of issuer $i$ with respect to the core yields are also spanned by a vector of common factors, $C F_{t}$, and an issuer-specific risk factor, $F_{t}^{i}$. 


$$
\begin{aligned}
y_{t, t+n}^{*} & =a_{n}^{*}+L_{t}+\frac{1-e^{-\lambda n}}{\lambda n} S_{t}+\left(\frac{1-e^{-\lambda n}}{\lambda n}-e^{-\lambda n}\right) C_{t} \\
y_{t, t+n}^{i} & =a_{n}^{i}+L_{t}+\frac{1-e^{-\lambda n}}{\lambda n} S_{t}+\left(\frac{1-e^{-\lambda n}}{\lambda n}-e^{-\lambda n}\right) C_{t} \\
& +b_{n}^{C F i^{\prime}} C F_{t}+b_{n}^{i} F_{t}^{i}
\end{aligned}
$$

The common spread factor may be set as a latent factor or a vector containing different components, such as market liquidity, $L q_{t}$, and common credit risk, $C r_{t}$. In a normal period, the liquidity premia may dominate the spreads (Favero et al., 2010); in a crisis mode, common credit risk may surge and exacerbate liquidity risk (Calice et al., 2013; Pelizzon et al., 2016). For a given maturity $n$, each yield has a different adjustment term, $a_{n}^{*}$ or $a_{n}^{i}$, which is determined by the underlying parameterizations that can be derived under the no-arbitrage conditions.

To model the core yield curve or any peripheral curve alone, it is sufficient to use the AFNS model or alternative forms of the typical affine term structure models. To model a peripheral yield curve with the aim of explaining its spreads against the core curve, an AFENS model is necessary to allow additional factors if they are observable (Li et al., 2011). In a yield net model where the three-layer factors together span the yield space, the factor structure not only reduces the dimension of yields, but also imposes additional restrictions in the risk-neutral process under the no-arbitrage condition, which, as we shall prove, shrinks the parameter space further.

\subsection{Factor structure across issuers given maturity}

Writing equations (3.1) and (3.2) in a compact matrix form, we get

$$
\mathbf{y}_{t, t+n}=\mathbf{a}_{n}+\mathbf{b}_{n}^{\prime} \mathbf{X}_{t}
$$

where

$$
\begin{aligned}
\mathbf{y}_{t, t+n} & =\left(\begin{array}{llll}
y_{t, t+n}^{*} & y_{t, t+n}^{1} & \cdots & y_{t, t+n}^{M}
\end{array}\right)^{\prime} \\
\mathbf{a}_{n} & =\left(\begin{array}{llll}
a_{n}^{*} & a_{n}^{1} & \cdots & a_{n}^{M}
\end{array}\right)^{\prime} \\
\mathbf{X}_{t} & =\left(\begin{array}{lllll}
X_{t}^{N S^{\prime}} & C F_{t}^{\prime} & F_{t}^{1} & \cdots & F_{t}^{M}
\end{array}\right)^{\prime}
\end{aligned}
$$


and

$$
\mathbf{b}_{n}=\left(\begin{array}{ccccc}
b_{n}^{*} & \cdots & \cdots & \cdots & b_{n}^{*} \\
0 & b_{n}^{C F_{1}} & \cdots & \cdots & b_{n}^{C F_{M}} \\
\vdots & b_{n}^{1} & 0 & \cdots & 0 \\
\vdots & 0 & \ddots & \ddots & \vdots \\
\vdots & \vdots & \ddots & \ddots & 0 \\
0 & 0 & \cdots & 0 & b_{n}^{M}
\end{array}\right)
$$

with $b_{n}^{*}=\left(\begin{array}{ccc}1 & \frac{1-e^{-\lambda n}}{\lambda n} & \frac{1-e^{-\lambda n}}{\lambda n}-e^{-\lambda n}\end{array}\right)^{\prime}$.

The factor structure is captured with the loading matrix $\mathbf{b}_{n}$. The zero restrictions in $\mathbf{b}_{n}$ enable factor identification through a physical process. This also implies a restricted structure in the risk-neutral process.

\subsection{Factor dynamics}

For the dynamics of state vector $\mathbf{X}_{t}$ under the physical measure, we assume that they satisfy a $\operatorname{VAR}(1)$ process with free parameters, $\mu$ and $\Phi$,

$$
\mathbf{X}_{t}=\mu+\Phi \mathbf{X}_{t-1}+v_{t} v_{t} \sim N(0, \boldsymbol{\Omega})
$$

Under the risk-neutral $\mathbb{Q}$ measure, the state vector $\mathbf{X}_{t}$ also follows a VAR process with identification restrictions under the factor structure in the measurement equations,

$$
\mathbf{X}_{t}=\mu^{Q}+\Phi^{Q} \mathbf{X}_{t-1}+v_{t}^{Q} \quad v_{t}^{Q} \sim N(0, \boldsymbol{\Omega})
$$

with $\mu^{Q}=\left(\begin{array}{c}\mu^{N S^{\mathbb{Q}}} \\ \mu^{c^{\mathbb{Q}}} \\ \mu^{1^{\mathbb{Q}}} \\ \vdots \\ \mu^{M^{\mathbb{Q}}}\end{array}\right), \Phi^{Q}=\left(\begin{array}{cccccc}\Phi^{N S^{\mathbb{Q}}} & \mathbf{0} & \ldots & \ldots & \ldots & \mathbf{0} \\ \mathbf{0} & \Phi^{C C^{\mathbb{Q}}} & \mathbf{0} & \ldots & \ldots & \mathbf{0} \\ \vdots & \Phi^{1 C^{\mathbb{Q}}} & \Phi^{11^{\mathbb{Q}}} & 0 & \ldots & 0 \\ \vdots & \vdots & 0 & \ddots & \ddots & \vdots \\ \vdots & \vdots & \vdots & \ddots & \ddots & 0 \\ \mathbf{0} & \Phi^{M C^{\mathbb{Q}}} & 0 & \ldots & 0 & \Phi^{M M^{\mathbb{Q}}}\end{array}\right)$, 
where $\Phi^{N S^{\complement}}=\left(\begin{array}{ccc}1 & 0 & 0 \\ 0 & e^{-\lambda} & \lambda e^{-\lambda} \\ 0 & 0 & e^{-\lambda}\end{array}\right)$.

We provide a detailed proof of the existence and uniqueness of the solution to this autoregressive parameter matrix $\Phi^{Q}$ in the online supplement ${ }^{1}$. Its highly sparse parameterizations of $\Phi^{Q}$ guarantee parsimony. Under this form, we show that factor loadings in the yield equation (3.2) can be determined by closed-form functions of the underlying parameters.

\subsection{Parameters specification}

We carry out the analysis of parameters specification following Dai and Singleton (2000), Pericoli and Taboga (2008), and Hong et al. (2019). To identify the common and individual credit risk factors, corresponding restrictions are imposed accordingly.

1) Identification of the NS factors. We set $\mathbf{a}_{1}=\left[\begin{array}{llll}0 & \cdots & 0\end{array}\right]^{\prime}$ and $\mu^{Q}=\left[\begin{array}{llll}\mu^{L^{\mathbb{Q}}} & 0 & \cdots & 0\end{array}\right]^{\prime}$. This uses the moment condition of the short rate $r_{t}=L_{t}+S_{t}$, as in the traditional NS model. Because both level and slope are latent, restricting all elements but the first one in $\mu^{Q}$ to zero assists in unique identification.

2) Identification of the unobservable risk factors driving yield spreads. For country-specific risk factors, in the short rate equation for each peripheral country, we set the loading on its individual risk factor as 1 , that is, $b_{1}^{i}=1$ for $i=1, \cdots, M$. Furthermore, because the common credit risk is also unobservable, its factor loading on one of the peripheral short rates is set to 1 for normalization.

3) Positivity restrictions on risk premia factors. Because empirical studies show that typically there are positive liquidity and credit risk premia in the peripheral yield spreads, especially with sizable premia during a debt crisis, we set $b_{1}^{C F_{i}}=e^{\gamma_{i}}$ for the setting of a single common factor, or $b_{1}^{L q_{i}}=e^{\gamma_{i}}$ and $b_{1}^{C r_{i}}=e^{\delta_{i}}$ for $i=1, \cdots, M$, for the setting of a separate common liquidity and credit risk.

4) Identification of the common spread factors. In the setting of a single common spread factor, it can be identified from the above restrictions. In the case of multiple spread factors, additional information is needed for risk decomposition. One way is to proxy a

\footnotetext{
${ }^{1}$ see Appendix at https://ssrn.com/abstract $=3325686$
} 
risk component by an observable variable, such as a market liquidity measure, $L q_{t}$, in order to separate the common credit risk, $C r_{t}$. In this way, we have

$$
\begin{gathered}
\mathbf{C F}_{t}=\left(\begin{array}{cc}
L q_{t} & C r_{t}
\end{array}\right)^{\prime}, \\
\mathbf{b}_{\mathbf{n}}^{C F_{i}}=\left(\begin{array}{ll}
b_{n}^{L q_{i}} & b_{n}^{C r_{i}}
\end{array}\right)^{\prime},
\end{gathered}
$$

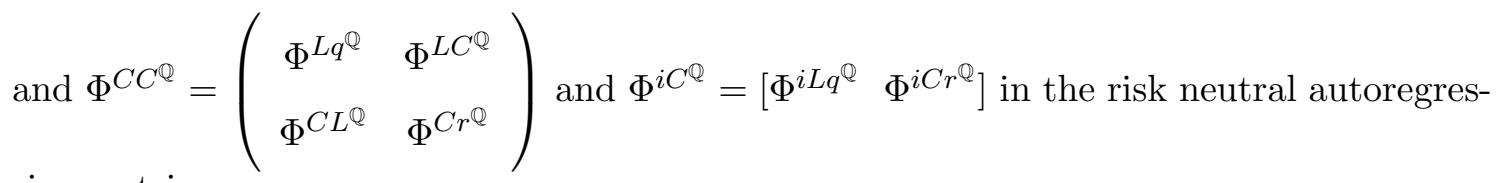
sive matrix.

The above specifications help identify the model parameters in general, which reduces the complexity of the estimation, maintains tractability, and enables economic interpretation. However, we impose additional orthogonality restrictions on the risk-neutral parameter space by setting $\Phi^{L C^{\mathbb{Q}}}=\Phi^{C L^{\mathbb{Q}}}=0$ and $\Phi^{i L q^{\mathbb{Q}}}=\Phi^{i C r^{\mathbb{Q}}}=0$ for $i=1, \cdots, M$.

Given the above specifications on parameters, the non-zero elements of the factor loading matrix $\mathbf{b}_{n}$ can be derived as closed-form functions of the underlying structural parameters in the building blocks.

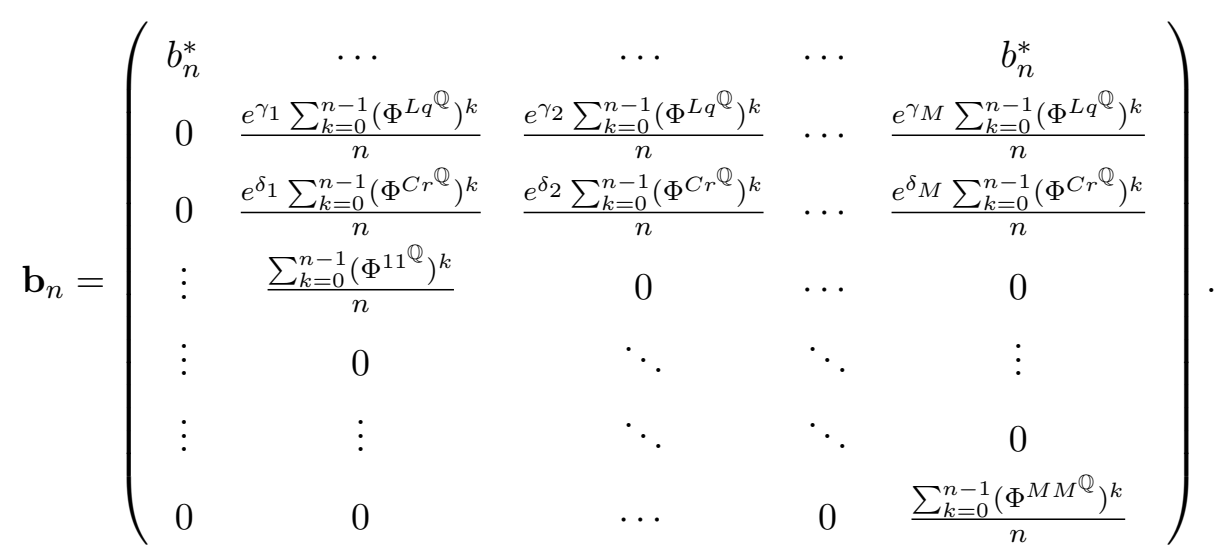

\subsection{Advantages of $A N^{1+M}$ model with respect to single curve models}

Compared to single curve models, which perform well in terms of in-sample fit or out-of-sample forecast, the $A N^{1+M}$ yield net model has clear advantages as follows:

1) It needs only a small number of factors to reduce the number of dimensions with economic underpinnings for the net as a whole. For $1+M$ yield curves, the AFNS single curve 
model needs $3+3 M$ factors altogether and does not provide a structural view of factor relationships, while the $A N^{1+M}$ model of one or two common spread factors needs $3+1+M$ or $3+2+M$ factors in total and allows for economic interpretation of factors with a perspective of risk sources; because $M \geq 2$, the net model needs fewer factors than $M$ AFNS models. Correspondingly, the parsimony of parameters will be maintained when the system is enlarged.

2) It has the capability of pricing yields of certain issuers with very sparse observations, such as Greece. Estimating an AFNS model of a certain issuer requires at least the yields of three proper maturities to disentangle the level, slope, and curvature factors in order to capture the entire curve. However, as in our illustration of Greece with only one maturity of 10-year yield available, its individual factor can still be pinned down and the implied yield curve can be reconstructed in our net setting. This is useful as a reference for pricing Greek bonds of other maturities or other Greek assets.

3) It has policy implications for risk surveillance and evaluations of policy interventions. For policy makers, the $A N^{1+M}$ joint model will be helpful for monitoring the sources and dynamics of risks. When a certain policy intervention is made, it will be possible to use the joint model to evaluate the policy's effectiveness in curbing local versus international risks.

\section{Estimation method}

The Bayesian approach with the MCMC method is widely used for estimation in the literature on yield curve modeling with highly nonlinear parameter space and latent factor dynamics. Examples include Ang et al. (2007), Hautsch and Yang (2012) and Bauer (2018). However, a typical single-move Gibbs sampler is not capable of dealing with the slow-mixing problem in such models with highly correlated latent states and non-linear parameters. Chib and Ergashev (2009) propose a marginalized approach to deal with this problem in a single curve affine term structure model. Similarly, we employ a marginal Metropolis-Hastings algorithm with multivariate proposals in the MCMC process tailored to the yield net and find it can effectively address the slow-mixing problem in a high-dimensional setting. 


\subsection{Econometric representation}

The econometric representation of our model can be written as

$$
\begin{aligned}
\mathbf{y}_{t} & =\mathbf{a}+\mathbf{b}^{\prime} \mathbf{X}_{t}+\varepsilon_{t}, \varepsilon_{t} \sim N(0, \Sigma) \\
\mathbf{X}_{t} & =\mu+\Phi \mathbf{X}_{t-1}+v_{t}, v_{t} \sim N(0, \Omega)
\end{aligned}
$$

where

$$
\begin{aligned}
\mathbf{y}_{t} & =\left(\begin{array}{llllllllll}
y_{t, t+n_{1}^{*}}^{*} & \ldots & y_{t, t+n_{k *}^{*}}^{*} & y_{t, t+n_{1}^{1}}^{1} & \ldots & y_{t, t+n_{k 1}^{1}}^{1} & \ldots & y_{t, t+n_{1}^{M}}^{M} & \ldots & y_{t, t+n_{k M}^{M}}^{M}
\end{array}\right)^{\prime}, \\
\mathbf{a} & =\left(\begin{array}{llllllllll}
a_{n_{1}^{*}}^{*} & \ldots & a_{n_{k *}^{*}}^{*} & a_{n_{1}^{1}}^{1} & \ldots & a_{n_{k 1}^{1}}^{1} & \ldots & a_{n_{1}^{M}}^{M} & \ldots & a_{n_{k M}^{M}}^{M}
\end{array}\right)^{\prime}, \\
\mathbf{b} & =\left(\begin{array}{lllllllllll}
\mathbf{b}_{n_{1}^{*}}^{*} & \ldots & \mathbf{b}_{n_{k *}^{*}}^{*} & \mathbf{b}_{n_{1}^{1}}^{1} & \ldots & \mathbf{b}_{n_{k 1}^{1}}^{1} & \ldots & \mathbf{b}_{n_{1}^{M}}^{M} & \ldots & \mathbf{b}_{n_{k M}^{M}}^{M}
\end{array}\right)^{\prime}, \\
\Sigma & =\operatorname{diag}\left(\begin{array}{llllllllll}
\sigma_{n_{1}^{*}}^{* 2} & \ldots & \sigma_{n_{k *}^{*}}^{* 2} & \sigma_{n_{1}^{1}}^{1^{2}} & \ldots & \sigma_{n_{k 1}^{1}}^{1^{2}} & \ldots & \sigma_{n_{1}^{M}}^{M^{2}} & \ldots & \sigma_{n_{k M}^{M}}^{M^{2}}
\end{array}\right),
\end{aligned}
$$

$a_{n}^{i}=-\mathbf{A}_{n}(i) / n, b_{n}^{i}=-\mathbf{B}_{n}(:, i) / n$ for $i=*, 1, \cdots, M$, and

$$
\begin{aligned}
& \mathbf{A}_{n}=\mathbf{A}_{n-1}+\mathbf{B}_{n-1}^{\prime} \mu^{Q}+\frac{1}{2} \operatorname{diag}\left(\mathbf{B}_{n-1}^{\prime} \Omega \mathbf{B}_{n-1}\right) \\
& \mathbf{B}_{n}=\Phi^{Q^{\prime}} \mathbf{B}_{n-1}+\mathbf{B}_{1} .
\end{aligned}
$$

Equations (4.1) and (4.2) constitute a state space representation with a set of underlying structural parameters, $\left\{\mu^{Q}, \Phi^{Q}, b_{1}^{C F}, \Omega\right\}$, to specify the coefficients in the observation function, $\mathbf{a}$ and b.

\subsection{Sampling procedure}

We need to estimate the parameters $\mu, \Phi, \Omega, \mu^{Q}, \Phi^{Q}, b_{1}^{C F}$ and $\Sigma$, and the latent variables in $\mathbf{X}=\left[\mathbf{X}_{1}, \cdots, \mathbf{X}_{T}\right]$. We set the prior and initial values based on a simple and fast procedure that combines a reduced-dimension optimization with multistep embedded regressions as in Hong et al. (2019). The main steps of the MCMC estimation are shown as follows for sampling iterations $s=1, \ldots, \bar{S}$.

1) Sampling of the latent variables involved in $\mathbf{X}_{t}$.

Given the observed yield data $\mathbf{y}=\left[\mathbf{y}_{1}, \cdots, \mathbf{y}_{T}\right]$, and the estimates drawn from the initial 
or the previous step, $\mu^{s-1}, \Phi^{s-1}, \Omega^{s-1}, \mu^{Q^{s-1}}, \Phi^{Q^{s-1}}, b_{1}^{C F^{s-1}}$ and $\Sigma^{s-1}$, we follow Kim and Nelson (1999) to use the standard Kalman filter to obtain the latent factors in $\mathbf{X}^{s}$.

2) Sampling of parameters $\mu$ and $\Phi$.

Given samplings of $\Omega^{s-1}$ and $\mathbf{X}^{s}$, we draw parameters $\Psi^{s}=\operatorname{vec}\left(\left[\mu^{s}, \Phi^{s}\right]\right)$ using Gibbs sampling from the distribution $N\left(\psi \mid \Omega^{s-1} \otimes\left(X^{s \prime} X^{s}\right)^{-1}\right)$.

3) Sampling of parameters $\mu^{Q}, \Phi^{Q}, b_{1}^{C F}$, and $\Omega$.

For this set of parameters entering the measurement equations in a highly nonlinear way, strong posterior correlations between parameters and states occur with typical single-move algorithms. To overcome this problem, we use the marginal Metropolis-Hastings algorith$\mathrm{m}$ to conduct directional sampling with local quadratic approximation on the marginal likelihood after integrating out the hidden states.

Let $\Gamma$ be the lower triangular matrix such that $\Gamma \Gamma^{\prime}=\Omega$. Denote $\Lambda$ as the set of parameters in $\mu^{Q}, \Phi^{Q}, b_{1}^{C F}$, and $\Gamma$. Then, we divide $\Lambda$ into $J$ blocks. For each block $\Lambda_{j}$, given samplings of other parameters, we draw $\Lambda_{j}^{\text {new }}$ from a multivariate normal distribution to approximate the posterior,

$$
q\left(\Lambda_{j}^{\text {new }} \mid \Lambda_{j}^{s-1}\right) \propto \exp \left\{\tilde{l}\left(\Lambda_{j} \mid \Lambda_{j}^{s-1}\right)\right\}
$$

where $\tilde{l}\left(\Lambda_{j} \mid \Lambda_{j}^{s-1}\right)=l\left(\Lambda_{j}^{s-1}\right)+\Delta l\left(\Lambda_{j}^{s-1}\right)\left(\Lambda_{j}-\Lambda_{j}^{s-1}\right)+\frac{1}{2}\left(\Lambda_{j}-\Lambda_{j}^{s-1}\right)^{\prime} \Delta^{2} l\left(\Lambda_{j}^{s-1}\right)\left(\Lambda_{j}-\Lambda_{j}^{s-1}\right)$ and $l\left(\Lambda_{j}\right)=\log p\left(\Lambda_{j} \mid \mathbf{y}, \Lambda_{j}^{-}\right)$is the logarithm of posterior density of $\Lambda_{j}$ which can be computed by the Kalman filter. The first and second derivatives of $l\left(\Lambda_{j}\right)$ are calculated using numerical methods.

Let

$$
\alpha=\max \left\{1, \frac{p\left(\mathbf{y}, \Lambda_{j}^{-}, \Lambda_{j}^{\text {new }}\right) q\left(\Lambda_{j}^{s-1} \mid \Lambda_{j}^{\text {new }}\right)}{p\left(\mathbf{y}, \Lambda_{j}^{-}, \Lambda_{j}^{s-1}\right) q\left(\Lambda_{j}^{\text {new }} \mid \Lambda_{j}^{s-1}\right)}\right\}
$$

then

$$
\Lambda_{j}^{s}=\left\{\begin{array}{ll}
\Lambda_{j}^{\text {new }} & \text { with probability } \alpha \\
\Lambda_{j}^{s-1} & \text { with probability } 1-\alpha
\end{array} .\right.
$$

4) Sampling of $\Sigma$

For $\Sigma$, the variance-covariance matrix of innovations in the measurement equation, we assume that each diagonal element ${\sigma_{n}^{i}}^{2}$ follows an inverse Gamma (IG) distribution, that 
is,

$$
{\sigma_{n}^{i}}^{2} \sim I G\left(c_{0}, d_{0}\right)
$$

and let $c_{0}=0$ for the non-informative prior, such that the posterior also follows an IG distribution,

$$
\sigma_{n}^{i^{2}} \sim \operatorname{IG}\left(\bar{c}_{n}^{i}, \bar{d}_{n}^{i}\right)
$$

where $\bar{c}_{n}^{i}=T$ and $\bar{d}_{n}^{i}=\sum_{t=1}^{T}\left(y_{t, t+n}^{i}-a_{n}^{i}-\mathbf{b}_{n}^{i^{\prime}} \mathbf{X}_{t}\right)^{2} / T$. Then we can take draws for the sample of $\Sigma^{s}$.

\subsection{Convergence diagnostics}

For a convergence check, we explore the MCMC diagnostic of Geweke (1992) to check convergence of the posterior distribution. Given any function of interest $g(\theta)$, if a sufficiently large number of draws has been taken, the estimate of $g(\theta)$ based on the last half should be equal to the estimate of an early part under the convergence assumption. We first divide our $S$ draws from the Gibbs sampler into an initial $S_{0}$ burn-in replications and the remaining $S_{1}$ draws, then we further divide $S_{1}$ into a first set of $S_{A}=0.2 S_{1}$ draws, a middle set of $S_{B}=0.5 S_{1}$, and a last set of $S_{C}=0.3 S_{1}$ draws. Let $\widehat{g}_{S_{A}}$ and $\widehat{g}_{S_{C}}$ be the estimates of $E[g(\theta) \mid y]$ using the $S_{A}$ replications

and $S_{C}$ replications, respectively. Define $\frac{\widehat{\sigma}_{A}}{\sqrt{S_{A}}}$ and $\frac{\widehat{\sigma}_{C}}{\sqrt{S_{C}}}$ as the numerical standard errors of these two estimates. Then, a central limit theorem of the familiar form under the weak conditions implies

$$
C D \stackrel{d}{\longrightarrow} N(0,1)
$$

where $C D$ is the convergence diagnostic given by

$$
C D=\frac{\widehat{g}_{S_{A}}-\widehat{g}_{S_{C}}}{\frac{\widehat{\sigma}_{A}}{\sqrt{S_{A}}}+\frac{\widehat{\sigma}_{C}}{\sqrt{S_{C}}}} .
$$

\subsection{Specification test}

In the empirical application, we need to test alternative assumptions on the model specification, such as the orthogonality of the variance-covariance matrix for shock identification, or the zero restrictions in the state dynamics. However, in such a high-dimensional and highly nonlinear model, to jointly infer latent factors and parameters, it is challenging to carry out specification tests with the typical tools of Bayes factors. In this paper, we use two types of tests for model 
diagnostics.

1) Posterior information criteria. Information criteria can be used with any model. In studies using Bayesian methods, the most common information criterion is the Bayesian Information Criterion (BIC)

$$
B I C(\theta)=2 \ln [p(y \mid \theta)]-K \ln (N)
$$

where $\theta, K, N$ and $p(y \mid \theta)$ are the vector of parameters, the number of parameters, the number of data points, and the likelihood, respectively. As shown in Schwarz et al. (1978), twice the log of the Bayes factor comparing two models is approximately equal to the difference in their BICs.

2) An MCMC output-based Bayesian model specification test (BMT). This test is proposed by Li et al. (2018), which combines two components, $J_{1}$ and $J_{0}$. The value of the $B M T=$ $J_{0}+J_{1}$ indicates whether the null model with certain restrictions is correctly specified; when the null is rejected, a large value of $J_{1}$ suggests that the misspecification is due to the restrictions. The derivation and computation of the test statistics are based on the MCMC result of the particular model. The detailed construction of the BMT for the AN model is shown in the online Appendix B.

\section{Data}

In this section, we first describe the bond yield data in our empirical study. We then discuss the construction of the market liquidity factor, which is used as an observable factor in order to extract the latent common credit risk from the co-movement of yield spreads.

\subsection{The yield data}

We obtain weekly data on government bond yields from Datastream for selected European countries. For each week, we take the yields of the last trading day, typically Friday if it is not a public holiday. The full sample is from October 2009 to November 2016, covering the whole period of the European debt crisis. For the illustrated $A N^{4}(3,2,3)$ model in the empirical analysis, the maturities of yields we use are 3 months and 1-10 years for Germany, and 2, 3, 5, 
7, and 10 years for Italy and Spain. Because the yield data for Greece for maturities less than 10 years were discontinued during the crisis, we only use the Greek 10-year yield ${ }^{2}$. In estimating the no-arbitrage model, we divide the original yield data in percentage terms by 5200 as $y_{n}$, with $n$ representing the number of weeks to maturity, so that $52 \times y_{n}$ corresponds to the annualized yield.

\subsection{The market liquidity risk factor}

To isolate market liquidity risk from the common credit risk of peripheral sovereign bonds, we use the estimated KfW-Bund spread as a proxy for the market liquidity factor, following Longstaff (2004), De Santis (2014), and Schwarz (2019) among others. Because the KfW (Kreditanstalt fuer Wiederaufbau) bonds and the German Bunds are both guaranteed by the German government, their default risks are assumed to be the same. Therefore, the differences between KfW and Bund yields (the KfW-Bund spread) measures the liquidity risk premia that reflect investors' preference for assets with the lowest liquidity risk. For periphery bonds, the liquidity premia also exist with respect to the Bunds in their spreads. The KfW-Bund spread serves as a proxy of liquidity risk and helps to isolate the components of credit risks in the peripheral bond spreads.

To construct the KfW-Bund spread, we retrieve transaction information about KfW bonds from Datastream, and estimate its zero-coupon equivalent yield curve using the Nelson-Siegel model (Nelson and Siegel, 1987), which is widely used in central banks of developed economies. The estimation details are explained in Gürkaynak et al. (2007). Then, based on the estimated KfW yield curve and the Bund yields, we take the 5-year KfW-Bund spread as a proxy of the liquidity factor, because 5-year KfW bonds are relatively more liquid and yields of the medium terms are estimated with better accuracy.

Figure 3 shows the estimated liquidity factor, the 5-year KfW-Bund spread, and the key European Central Bank (ECB) interest rates. This liquidity factor demonstrates a similar path with the three ECB key rates, especially before June 2014, when the ECB deposit facility rate turned negative. When the ECB injects liquidity into the market by cutting the key rates, the market liquidity factor falls correspondingly, reflecting higher liquidity resulting from policy interventions. However, after the ECB introduced a negative policy rate, followed by its

\footnotetext{
${ }^{2}$ Due to the singular observation of the Greek 10-year yield at each point in time, we have to set $\Phi^{G R^{\mathbb{Q}}}=1$ in the risk-neutral coefficient matrix for identification.
} 
Expanded Asset Purchase Programme (EAPP) or quantitative easing (QE), in January 2015, the KfW liquidity indicator stayed steadily above the marginal lending facility rate, indicating that the market liquidity did not improve further with the QE measures.

[Figure 3. The market liquidity factor and ECB key interest rates]

\section{Empirical Application}

In this section, we apply the yield net model to the European sovereign bond yields of Germany, Italy, Spain, and Greece by estimating two specifications of a $A N^{4}(3,2,3)$ model and conducting in-depth analysis. We make a total of 20,000 draws and burn in the first 4,000 draws for a given specification. The yield net modeling framework provides us tools for examining the risk transmission. Without specific information on the shocks, a typical identification strategy is to impose restrictions on $\Omega$, such as a diagonal $\Omega$ based on the assumption of orthogonal shocks. To test this assumption, we estimate both unrestricted and restricted versions of the $A N^{4}(3,2,3)$ model.

\subsection{Convergence check and specification test}

Table 1 reports the CD test results of the $A N^{4}(3,2,3)$ of German, Italian, Spanish, and Greek yields for the two model specifications. It shows that, except for a couple of risk-neutral parameters in the unrestricted specification with non-diagonal $\Omega$, all the parameters converge, especially in the diagonal $\Omega$ specification.

[Table 1. Summary of the convergence diagnostics for $A N^{4}(3,2,3)$ ]

We use two types of tests to compare the two model specifications, i.e., the posterior BIC test and an MCMC output-based test, BMT, proposed by Li et al. (2018). As shown in Table 2, the BIC test favors the restricted model, i.e., a diagonal $\Omega$ of orthogonal shocks, while the BMT test rejects both cases with $J 0+J 1$ being far higher than the critical value. For a better understanding, we also test the orthogonal assumption on shocks using the AFNS models of German, Italy, and Spain, which is also shown in this table. The BMT test also rejects most of the restricted AFNS models with large values of $J 0+J 1$. However, a smaller $J 1$ than the critical value in the AFNS indicates that the rejection is not due to the diagonal setting of $\Omega$, 
giving a green light to the diagonal restriction conditional on the chosen model. According to the above specification analysis, in what follows, we will present empirical results based on the restricted model with diagonal $\Omega$.

[Table 2. Posterior BIC and BMT test results for $A N^{4}(3,2,3)$ and AFNS models]

\subsection{Parameter estimation}

1) Parameters under the risk-neutral measure. Table 3 presents the VAR parameters under the risk-neutral measure. The diagonal autoregressive parameters, $\Phi^{L q^{\mathbb{Q}}}, \Phi^{C r^{\mathbb{Q}}}$, and $\Phi^{I T^{\mathbb{Q}}}$, determine the decaying speed of their corresponding factor loadings as maturity $n$ increases. Because their estimates are all close to 1, such that the related loadings are highly persistent along $n$, peripheral yields at all maturities are remarkably exposed to various spread risks.

[Table 3. The VAR parameters under the risk-neutral measure]

2) Factor loadings. Table 4 reports factor loadings of short rates of peripheral countries on market liquidity risk and common sovereign credit risk. By comparison, Greece faces the most severe exposure to both risks with the highest loadings $b_{1}^{C r}$ and $b_{1}^{L q}$. For Italy and Spain, their exposures to common credit risk are similar, yet Italy has higher exposure to liquidity risk. Overall, the factor loadings are largely in line with the economic fundamentals of these countries: weaker fundamentals correspond to higher risk exposure. The factor loadings for the whole yield curves are shown in Figure 4. We can see that the common credit risk is a level factor in spread, with flat loadings of a slowly decaying rate along maturity due to its high persistence. In contrast, the liquidity factor is a slope factor with decreasing impact along maturity.

[Table 4. Factor loadings of short rates on the market liquidity risk and common sovereign credit risk]

[Figure 4. The factor loadings on liquidity and common sovereign credit risk factors] 
3) Parameters under the physical measure. Table 5 presents parameter estimation of the state VAR under the physical measure. Focusing on the VAR coefficient matrix $\Phi$, we find that the lagged market liquidity risk has significant effect on the NS factors of the core curve. It also shows that country-specific risks do spill over to each other. For example, the lagged Italian risk factor has a significantly positive effect on the Greek factor, indicating that contagion is likely to spread first to the weakest economy.

[Table 5. VAR parameters under the physical measure]

4) Goodness of model fit. Table 6 shows the goodness of fit from the $A N^{4}(3,2,3)$ settings with comparison to AFNS model for each single yield curve. The joint fit of $A N^{4}(3,2,3)$ model is remarkable for Germany. The fit for Italy and Spain is not as good as the AFNS, but errors around 10 basis points for yield curve fitting in a crisis period seems acceptable. Since only the 10-year yield of Greece is available through the whole sample, the AFNS model cannot be applied to Greek yield, but the $A N^{4}(3,2,3)$ model can still price the Greece yield curve through its net structure.

[Table 6. Goodness of fit comparison for $A N^{4}(3,2,3)$ and AFNS models]

\subsection{Dynamics of extracted factors}

Figure 5 depicts the extracted NS factors. Figure 6 plots the latent spread factors identified from the factor structure across yield curves. The solid lines are medium from the posterior distribution, and the dashed lines indicate the [5\%, 95\%] confidence interval with a shaded area in between.

[Figure 5. The three Nelson-Siegel factors of German Bunds]

[Figure 6. The common and country-specific credit risk factors]

1) NS factors of German yields. In Figure 5, the level factor shows a downward trend and the slope factor an upward trend, corresponding to a flattening pattern of the German yield curve during the crisis.

2) Country-specific risk factors. In Figure 6, the three individual factors exhibit different dynamic characteristics, though the Italian and Spanish factors still share some common 
patterns. The spikes during the crisis period often correspond to specific events. For example, downgrading of credit ratings from international rating agencies often triggers rising tides in spreads, such as those in May 2010 for Greece, and mostly visible also for Spain. The Italian factor surged to an unprecedented level in November 2011 after Fitch, a credit rating agency, cut its credit rating from AA- to $\mathrm{A}+$. The risk factors began to decline in December 2011 as the ECB began to inject a huge amount of credit into the banking system with exceptionally low rates. A bailout package in July 2010 for Greece temporarily mitigated its risk level, and a second bailout agreement of 130 billion euros in March 2012 sharply reduced its risk, but a general election in May 2012 to reject the bailout agreement increased the risk again.

3) Common sovereign credit risk factor. In contrast to country-specific factors, the common sovereign credit risk factor in Figure 6 shows a persistent upward trend until the fall of 2012, shortly after the ECB president made a landmark speech that the bank would do "whatever it takes" to save the euro, followed by cutting interest rates with massive credit easing operations.

\subsection{Reconstructing the yield curve for Greece}

Even though the Greek data has only a 10-year maturity yield throughout the sample, the yield net model is capable of constructing the entire Greek yield curve, which is impossible with a single curve model or statistical factor models. Figure 7 shows the implied Greek yield curve at two different dates, inferred from the yield net. This property of the model is helpful for pricing bonds of an issuer with sparse transactions, and for providing investors a useful reference for pricing various assets when the official yield curve is incomplete.

[Figure 7. Greek yield curve implied by the $A N^{4}(3,2,3)$ model]

\subsection{Yield decomposition into expectation and risk premia}

Compared to a statistical yield factor model, the advantage of a no-arbitrage model is in its structural interpretation. We decompose 10-year yields for the implication on expectations and risk premia for long-term bonds, shown in Figure 8. The expected German yields are below zero throughout the whole sample, indicating an expected long-term decline of the benchmark yield 
in Europe with the pessimistic path of the economy. The expected 10-year yields of Italy and Spain gradually slide into the negative region after the QE was initiated. The expected yield of Greece remains high, reflecting the haircut from its debt mark-down, while the negative premia seem to imply optimism about debt holders' coverage by various bailout plans in progress.

[Figure 8. 10-year yield decomposition]

To understand how each factor determines the yield decomposition across maturities, we can compute the implied loadings of a specific factor on yield expectation and risk premia. Take the common credit risk factor, for example, its overall loadings on yields are shown in Figure 4. Figure 9 and 10 show the decomposed loadings. We can see from Figure 9 that the loadings of expected yields on common credit risk are downward sloping, implying that the expected effect of the common credit risk declines on long-term yield as the expected short-term interest rate trends down in expectation. On the contrary, the loadings of risk premia slope upward in Figure 10, as long-term bonds face higher uncertainty of credit risk in the holding period.

[Figure 9. The factor loadings of expected yields on common sovereign credit risk factors]

[Figure 10. The factor loadings of risk premia on common sovereign credit risk factors]

\subsection{Risk transmission analysis}

Figure 11 and 12 show the impulse response functions (IRFs) to market liquidity and common sovereign credit risks, respectively. Each row corresponds to the yield responses of one country, and the columns correspond to the 3-month, 1-year, 5-year, and 10-year yields. The German yields are in the first row, followed by Italy, Spain, and Greece. This figure shows that, in response to liquidity and common sovereign credit risk shocks, yields of all peripheral countries rose significantly for at least 10 weeks. The weaker the economic foundation, the stronger the responses.

[Figure 11. Impulse responses of government bond yields to shocks of the liquidity risk factor]

[Figure 12. Impulse responses of government bond yields to shocks of the common sovereign credit risk factor]

Figure 13 shows the IRFs of the country-specific risk factors to each other. Each row reports a specific factor's response to shocks from the three peripheral countries. A significant response 
on the off-diagonal positions indicates a spillover effect. A positive spillover implies contagion. For example, the first column shows that risks originating in Italy, the third largest economy of the euro area, significantly spilled over to Greece, the most vulnerable country with the worst fundamentals.

[Figure 13. Impulse responses of country-specific risk factors to shocks of other countries]

\section{Conclusion}

We develop an arbitrage-free yield net model with a core-periphery structure for multiple yield curves. The model achieves good fit for the yield curves of Germany, Italy, and Spain during the euro debt crisis, with strong identification of risk factors from different sources. With only 10-year yield data for Greece, the model is capable of identifying Greece's individual risk factor and providing information for Greece's implied yield curve. It successfully explains the dramatic movement of peripheral yield spreads with the underlying common and individual factors in a parsimonious setting. The model enables us to analyze the interaction between factors and their effects on yields across maturities and countries with consistency and tractability.

A beneficial direction of future research will be to extend the model to accommodate state dynamics with changing parameters, which can be used to monitor varying effects of risk factors during a debt crisis. Another direction worth taking is to use the BMT test for further specification analysis with the goal of better understanding the correlation structure of various risk innovations.

\section{Acknowledgments}

We are grateful for helpful discussions with Agostino Consolo, Carlo Favero, Andras Fulop, Felix Hammermann, Junye Li, Ming Lin, Loriana Pelizzon, and Tao Zeng. We are also grateful for comments of seminar and conference participants at Deutsche Bundesbank, Humboldt University of Berlin, Xiamen University, Shanghai Jiaotong University, Aarhus University, Auckland University, Zhejiang University, and ESSEC Business School (Singapore). We especially thank the issue editor, Prof. Jun Yu, and one of the anonymous referees for their valuable suggestions and constructive comments to significantly improve the quality of the paper. All errors are our responsibility. This work was supported by the National Natural Science Foundation of China 
[grant numbers 71871193 and 72033008] and Volkswagen Foundation for the project of QE and Financial (In)stability.

\section{Appendix: Proofs}

The theoretical proofs are presented in the form of supplementary material, which can be found online at https://ssrn.com/abstract $=3325686$.

\section{References}

Adam, T., Lo Duca, M., 2017. Modeling euro area bond yields using a time-varying factor model. ECB Working Paper No.2012.

Aït-Sahalia, Y., Laeven, R. J. A., Pelizzon, L., 2014. Mutual excitation in Eurozone sovereign CDS. Journal of Econometrics 183 (2), 151-167.

Ang, A., Dong, S., Piazzesi, M., 2007. No-arbitrage Taylor rules. NBER Working Paper No.13448.

Ang, A., Longstaff, F. A., 2013. Systemic sovereign credit risk: Lessons from the US and Europe. Journal of Monetary Economics 60 (5), 493-510.

Ang, A., Piazzesi, M., 2003. A no-arbitrage vector autoregression of term structure dynamics with macroeconomic and latent variables. Journal of Monetary economics 50 (4), 745-787.

Antonakakis, N., Vergos, K., 2013. Sovereign bond yield spillovers in the Euro zone during the financial and debt crisis. Journal of International Financial Markets, Institutions and Money $26,258-272$.

Bauer, M. D., 2018. Restrictions on risk prices in dynamic term structure models. Journal of Business and Economic Statistics 36 (2), 196-211.

Beber, A., Brandt, M. W., Kavajecz, K. A., 2009. Flight-to-quality or flight-to-liquidity? Evidence from the euro-area bond market. Review of Financial Studies 22 (3), 925-957.

Beetsma, R., Giuliodori, M., De Jong, F., Widijanto, D., 2013. Spread the news: The impact 
of news on the European sovereign bond markets during the crisis. Journal of International Money and Finance 34, 83-101.

Bi, H., 2012. Sovereign default risk premia, fiscal limits, and fiscal policy. European Economic Review 56 (3), 389-410.

Bi, H., Leeper, E. M., 2010. Sovereign debt risk premia and fiscal policy in Sweden. NBER Working Paper No.15810.

Calice, G., Chen, J., Williams, J., 2013. Liquidity spillovers in sovereign bond and CDS markets: An analysis of the Eurozone sovereign debt crisis. Journal of Economic Behavior and Organization 85, 122-143.

Chib, S., Ergashev, B., 2009. Analysis of multifactor affine yield curve models. Journal of the American Statistical Association 104 (488), 1324-1337.

Christensen, J. H., Diebold, F. X., Rudebusch, G. D., 2011. The affine arbitrage-free class of Nelson-Siegel term structure models. Journal of Econometrics 164 (1), 4-20.

Christensen, J. H., Lopez, J. A., Rudebusch, G. D., 2014. Do central bank liquidity facilities affect interbank lending rates? Journal of Business \& Economic Statistics 32 (1), 136-151.

Cox, J. C., Ingersoll Jr, J. E., Ross, S. A., 1985. A theory of the term structure of interest rates. Econometrica 53(2), 385-408.

Dai, Q., Singleton, K. J., 2000. Specification analysis of affine term structure models. The Journal of Finance 55 (5), 1943-1978.

De Santis, R. A., 2014. The euro area sovereign debt crisis: Identifying flight-to-liquidity and the spillover mechanisms. Journal of Empirical Finance 26, 150-170.

Dewachter, H., Iania, L., Lyrio, M., de Sola Perea, M., 2015. A macro-financial analysis of the euro area sovereign bond market. Journal of Banking and Finance 50, 308-325.

Diebold, F. X., Li, C., 2006. Forecasting the term structure of government bond yields. Journal of Econometrics 130 (2), 337-364.

Duffie, D., Singleton, K. J., 1999. Modeling term structures of defaultable bonds. Review of Financial Studies 12 (4), 687-720. 
Duffie, D., Singleton, K. J., 2012. Credit risk: pricing, measurement, and management. Princeton University Press.

Ehrmann, M., Fratzscher, M., 2017. Euro area government bonds: Fragmentation and contagion during the sovereign debt crisis. Journal of International Money and Finance 70, 26-44.

Favero, C., Missale, A., 2012. Sovereign spreads in the eurozone: which prospects for a Eurobond? Economic Policy 27 (70), 231-273.

Favero, C., Pagano, M., Von Thadden, E.-L., 2010. How does liquidity affect government bond yields? Journal of Financial and Quantitative Analysis 45 (1), 107-134.

Favero, C. A., 2013. Modelling and forecasting government bond spreads in the euro area: A GVAR model. Journal of Econometrics 177 (2), 343-356.

Garcia, J. A., Gimeno, R., 2014. Flight-to-liquidity flows in the euro area sovereign debt crisis. Bank of Spain Working Paper No.1429.

Geweke, J., 1992. Evaluating the accuracy of sampling-based approaches to the calculation of posterior moments. Bayesian Statistics 4, 169-188.

Giordano, R., Pericoli, M., Tommasino, P., 2013. Pure or wake-up-call contagion? Another look at the EMU sovereign debt crisis. International Finance 16 (2), 131-160.

Gürkaynak, R. S., Sack, B., Wright, J. H., 2007. The US Treasury yield curve: 1961 to the present. Journal of Monetary Economics 54 (8), 2291-2304.

Hautsch, N., Yang, F., 2012. Bayesian inference in a stochastic volatility Nelson-Siegel model. Computational Statistics and Data Analysis 56 (11), 3774-3792.

Hong, Z., Niu, L., Zeng, G., 2019. US and Chinese yield curve responses to RMB exchange rate policy shocks: An analysis with the arbitrage-free Nelson-Siegel term structure model. China Finance Review International 9 (3), 360-385.

Joslin, S., Priebsch, M., Singleton, K. J., 2014. Risk premiums in dynamic term structure models with unspanned macro risks. The Journal of Finance 69 (3), 1197-1233.

Kim, C. J., Nelson, C. R., 1999. State-space models with regime switching: classical and Gibbssampling approaches with applications. MIT Press Books. 
Li, C., Niu, L., Zeng, G., 2011. A generalized arbitrage-free Nelson-Siegel term structure model with macroeconomic fundamentals. Available at SSRN: https://ssrn.com/abstract=1787262.

Li, Y., Yu, J., Zeng, T., 2018. Specification tests based on MCMC output. Journal of Econometrics 207 (1), 237-260.

Longstaff, F., 2004. The Flight-to-Liquidity Premium in US Treasury Bond Prices. The Journal of Business 77 (3), 511-526.

Monfort, A., Renne, J. P., 2014. Decomposing euro-area sovereign spreads: credit and liquidity risks. Review of Finance 18 (6), 2103-2151.

Nelson, C. R., Siegel, A. F., 1987. Parsimonious Modeling of Yield Curves. Journal of Business $60(4), 473-489$.

Pelizzon, L., Subrahmanyam, M. G., Tomio, D., Uno, J., 2016. Sovereign credit risk, liquidity, and European Central Bank intervention: Deus ex machina? Journal of Financial Economics $122(1), 86-115$.

Pericoli, M., Taboga, M., 2008. Canonical term-structure models with observable factors and the dynamics of bond risk premia. Journal of Money, Credit and Banking 40 (7), 1471-1488.

Schwarz, G., et al., 1978. Estimating the dimension of a model. The Annals of Statistics 6 (2), 461-464.

Schwarz, K., 2019. Mind the gap: Disentangling credit and liquidity in risk spreads. Review of Finance 23 (3), 557-597.

Vasicek, O., 1977. An equilibrium characterization of the term structure. Journal of Financial Economics 5 (2), 177-188. 


\section{Figures and Tables}

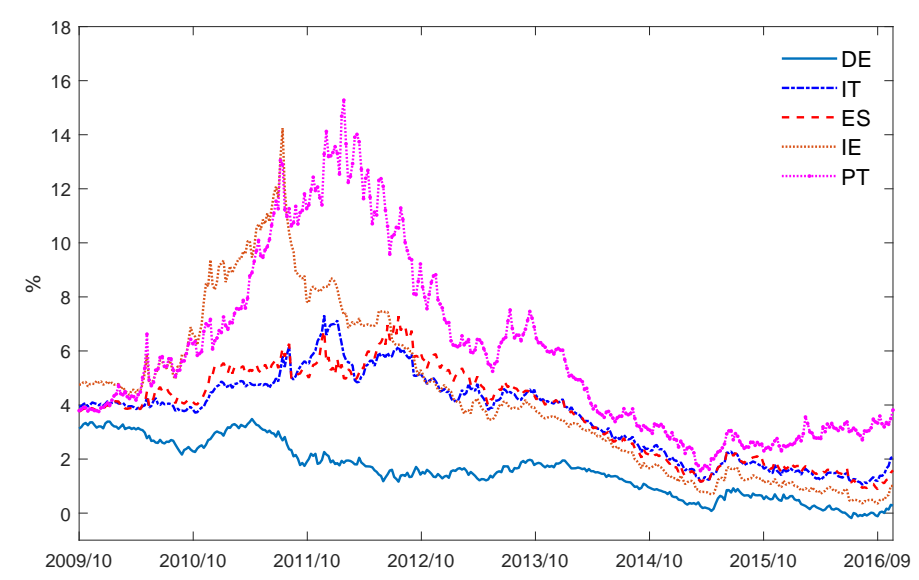

Figure 1. 10-year government bond yields of Germany, Italy, Spain, Ireland and Portugal
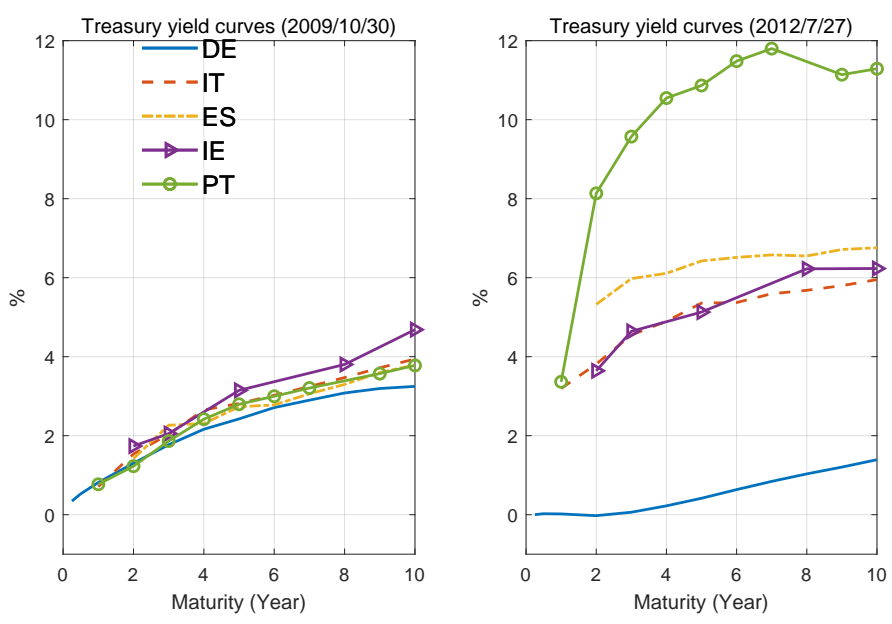

Figure 2. A euro yield net at two dates: $2009 / 10 / 30$ vs. 2012/07/27 


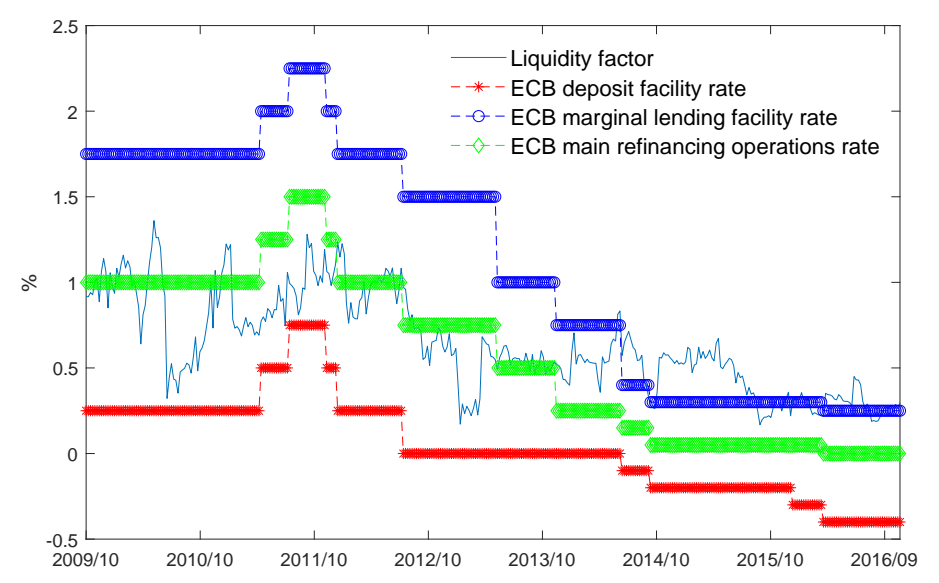

Figure 3. The common market liquidity factor and ECB key interest rates
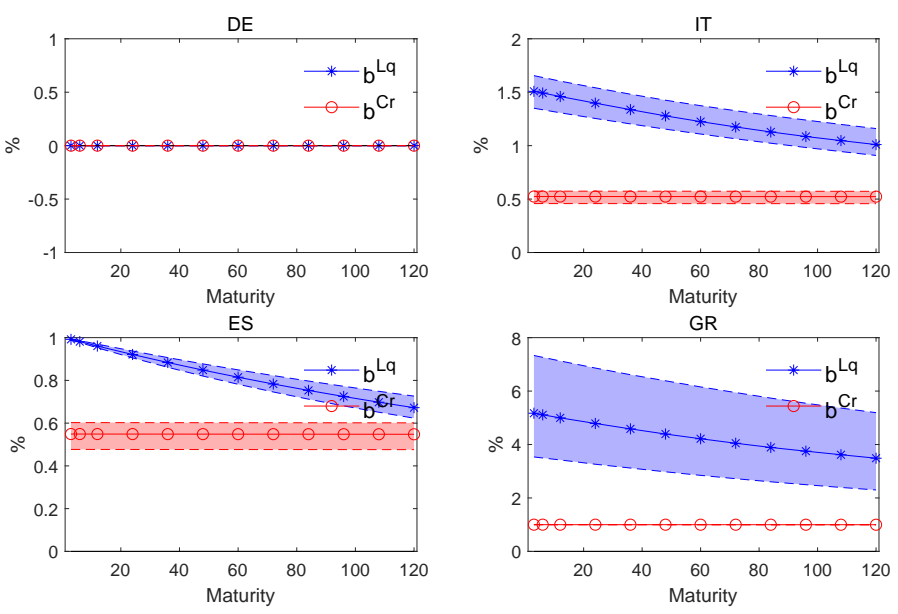

Note: The solid lines are the median of the posterior distribution, and the shadow areas indicate the [5\%, 95\%] confidence interval.

Figure 4. The factor loadings on liquidity and common credit sovereign risk factors 

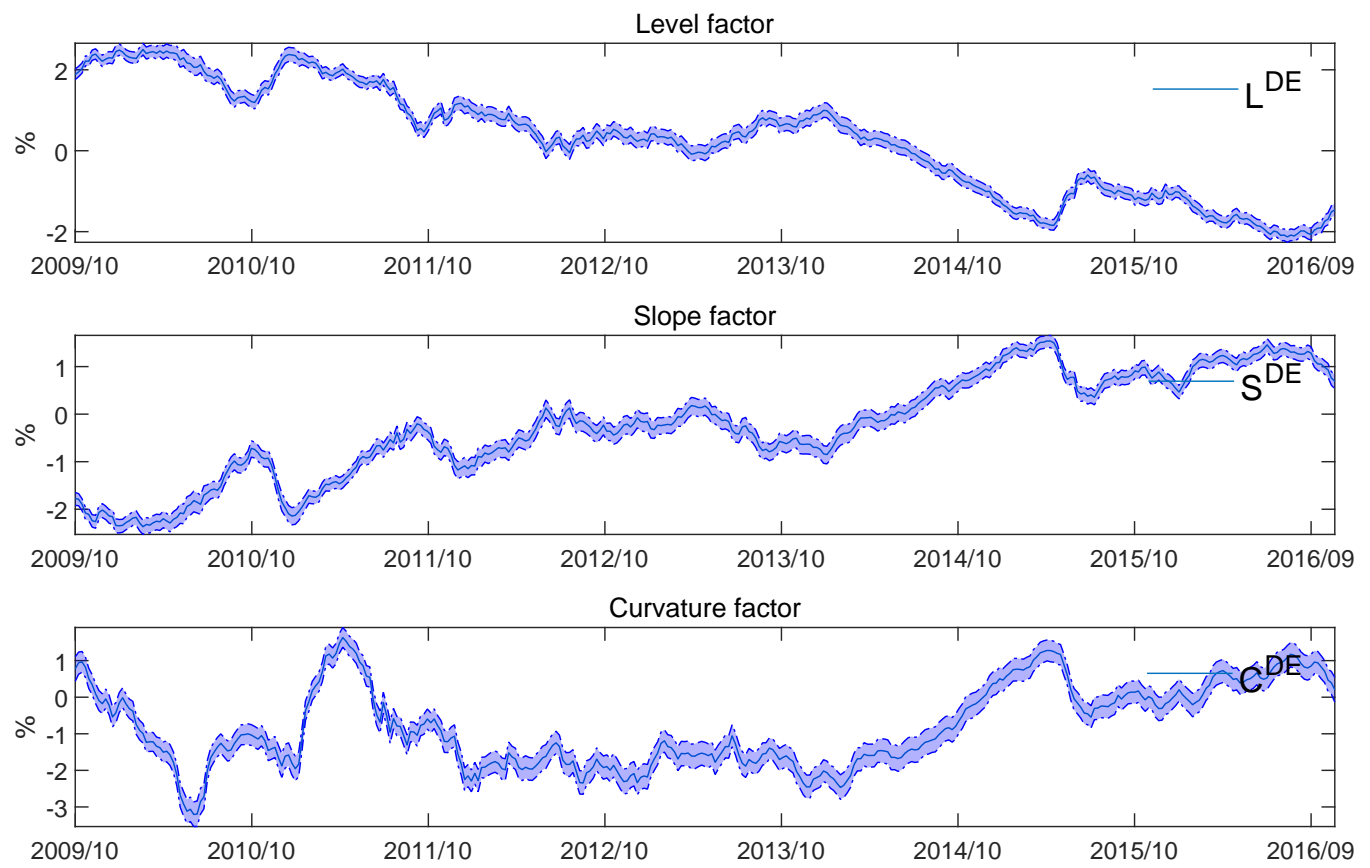

Note: The solid lines are the median of the posterior distribution, and the shadow areas indicate the [5\%, 95\%] confidence interval.

Figure 5. The three Nelson-Siegel factors of German Bunds 

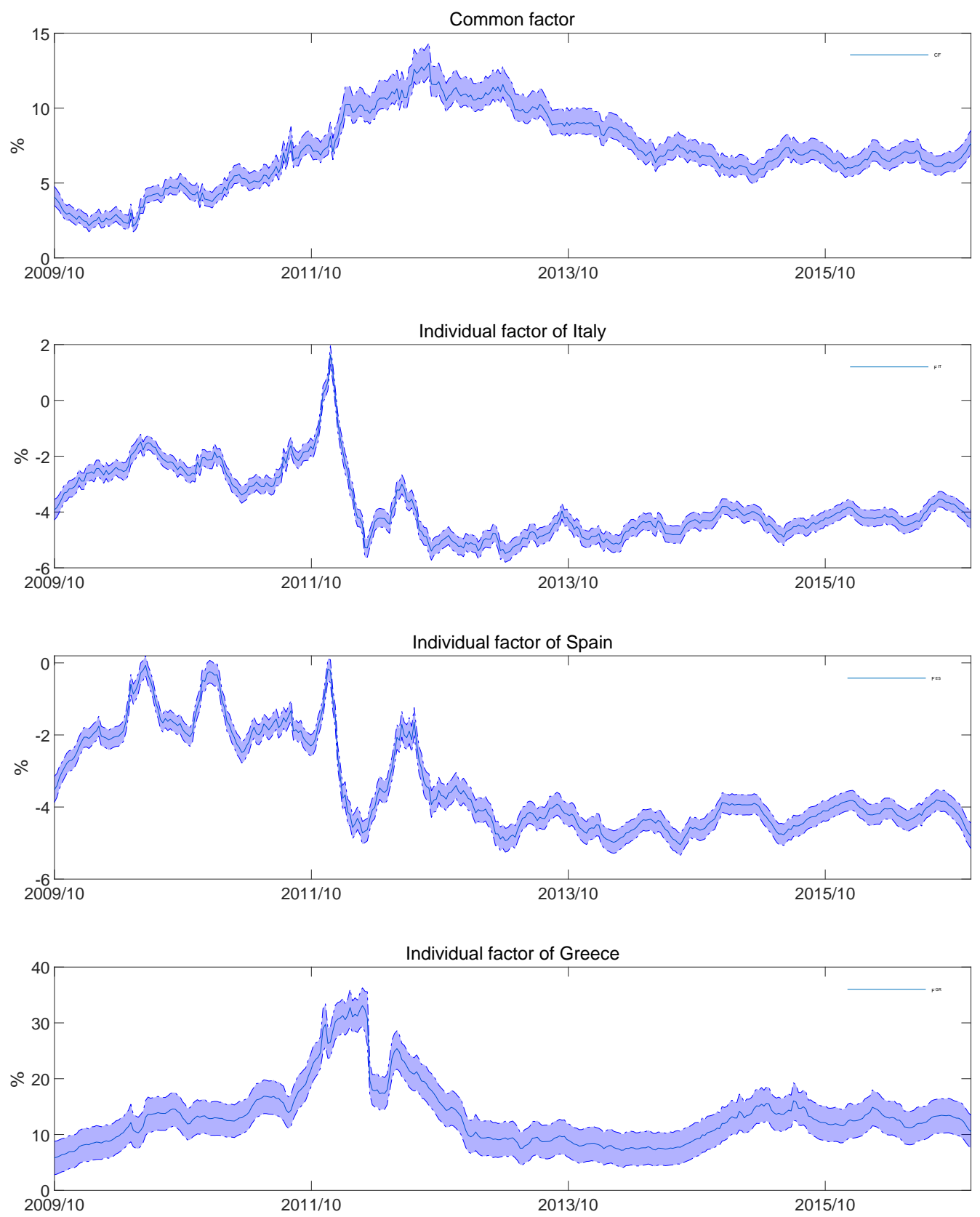

Note: The solid lines are the median of the posterior distribution, and the shadow areas indicate the [5\%, 95\%] confidence interval.

Figure 6. The common credit risk factor and country-specific credit risk factors 


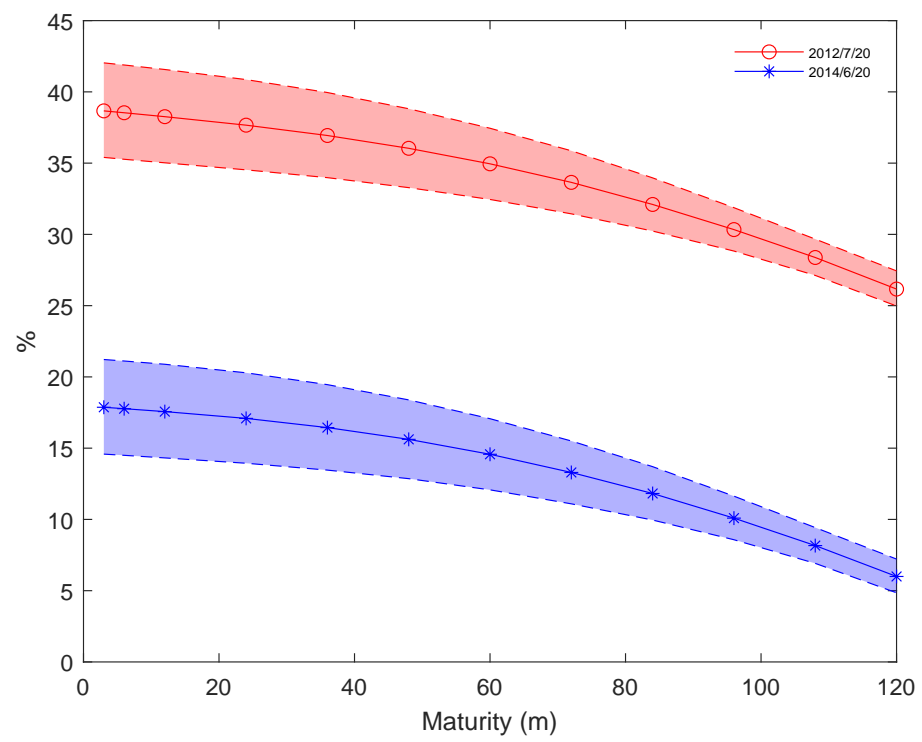

Note: This figure shows the yield curves on $2012 / 7 / 20$ and $2014 / 6 / 20$ implied by the $A N^{4}(3,2,3)$ model. The solid lines are medium from posterior distribution, and the shadow areas indicate the [5\%,95\%] confidence interval.

Figure 7. Greek yield curve implied by the $A N^{4}(3,2,3)$ model
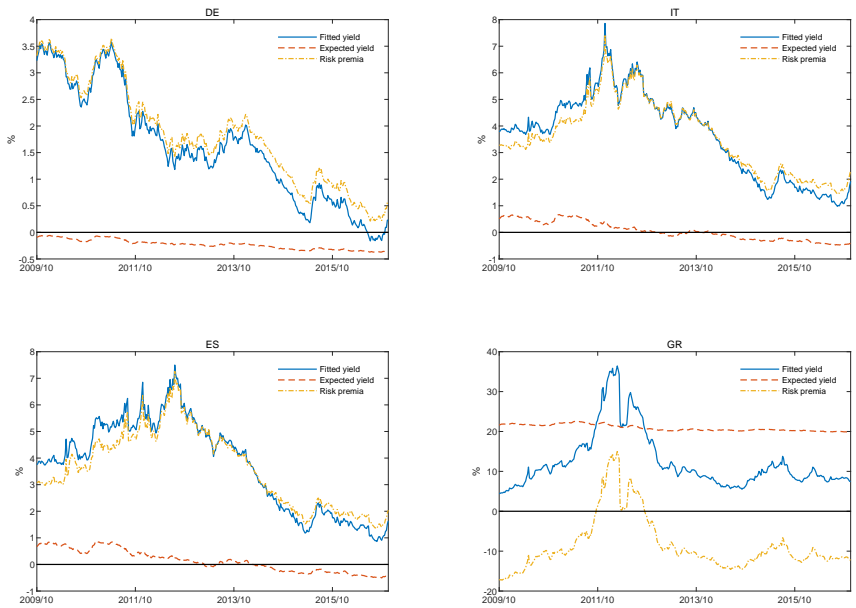

Figure 8. 10-year yield decomposition 

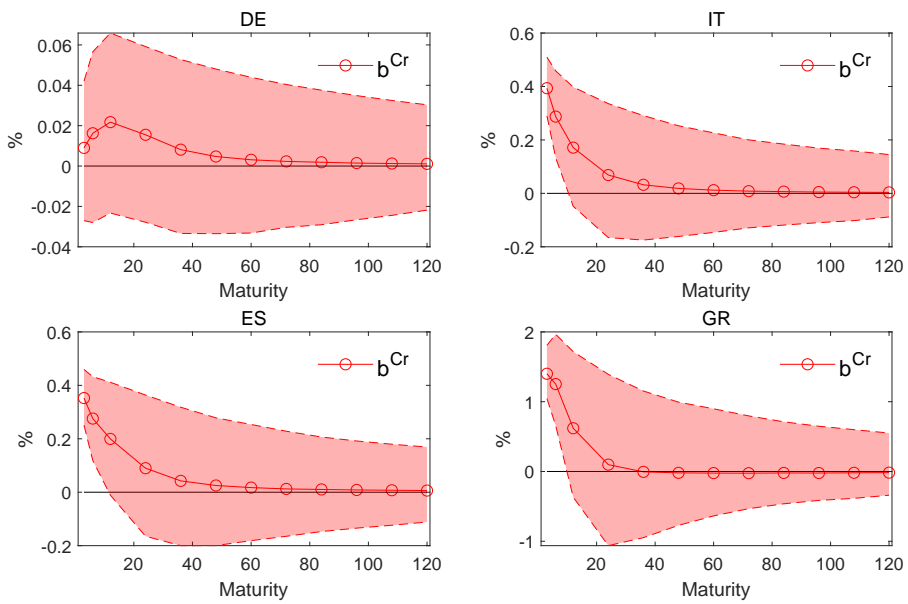

Note: The solid lines are the median of the posterior distribution, and the shadow areas indicate the [5\%, 95\%] confidence interval.

Figure 9. The factor loadings of expected yield on common sovereign credit risk factors
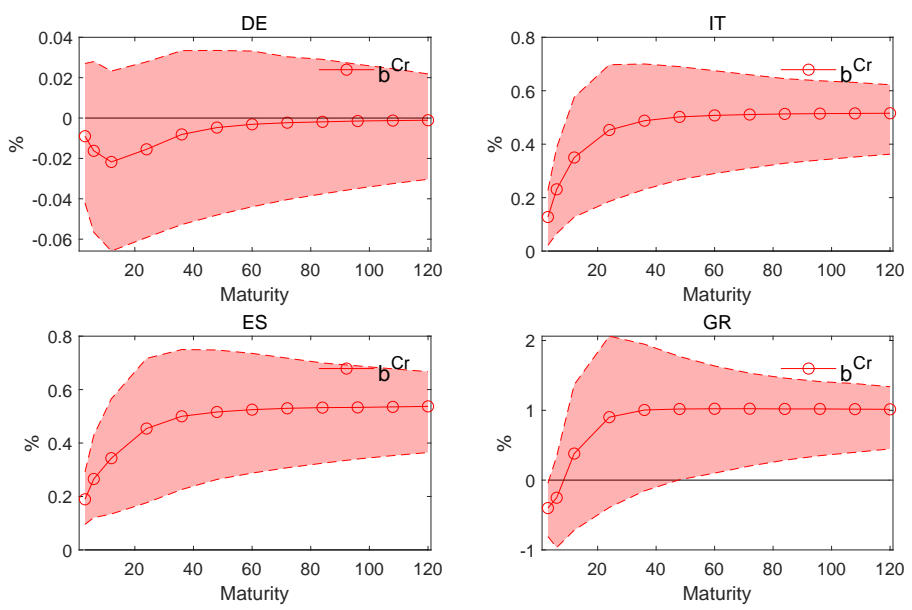

Note: The solid lines are the median of the posterior distribution, and the shadow areas indicate the [5\%, 95\%] confidence interval.

Figure 10. The factor loadings of risk premia on common sovereign credit risk factors 

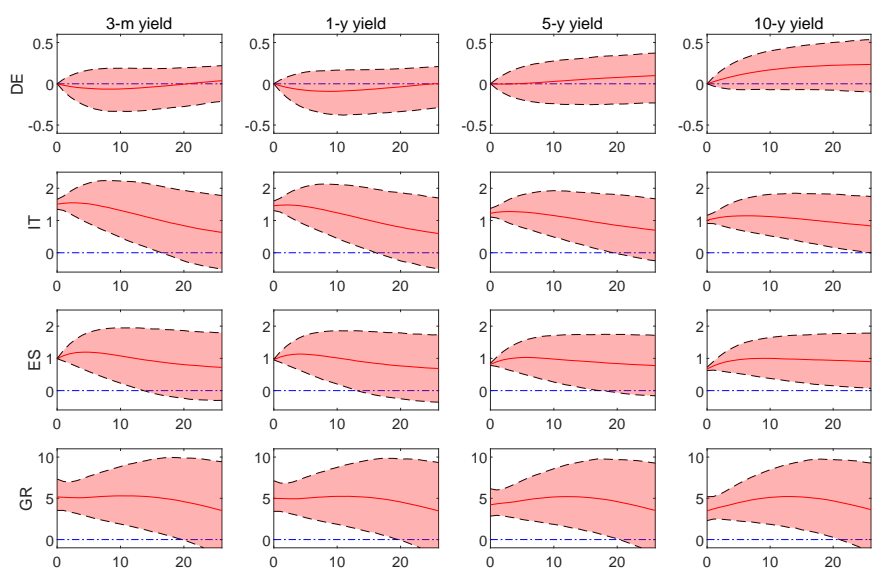

Note: The solid lines are the median of the posterior distribution, and the shadow areas indicate the [5\%, 95\%] confidence interval.

Figure 11. Impulse responses of government bond yields to shock of the liquidity risk factor
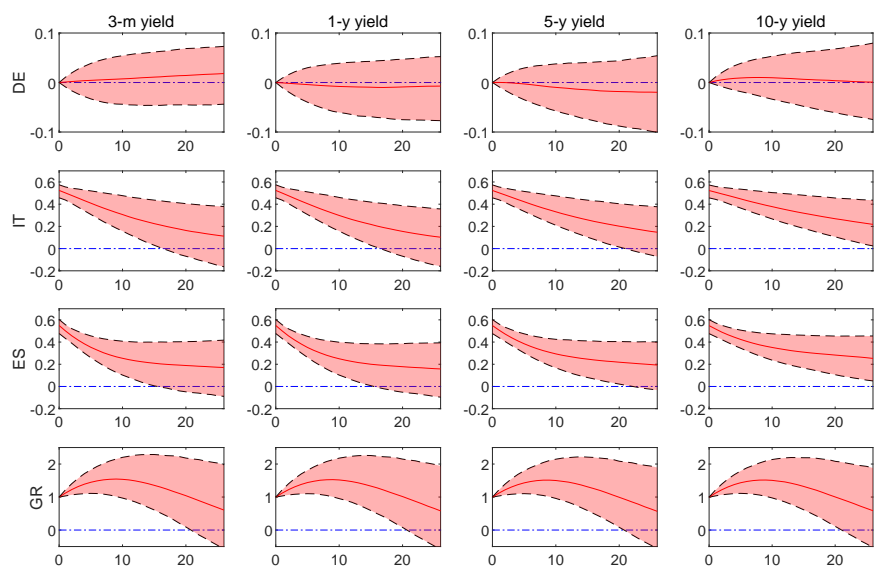

Note: The solid lines are the median of the posterior distribution, and the shadow areas indicate the [5\%, 95\%] confidence interval.

Figure 12. Impulse responses of government bond yields to shock of the common sovereign credit risk factor 

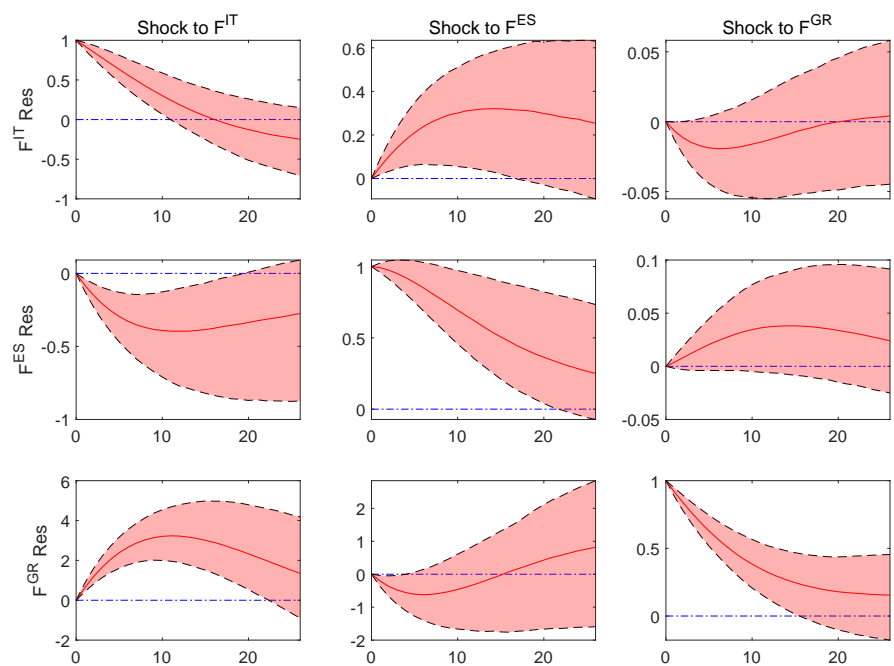

Note: The solid lines are the median of the posterior distribution, and the shadow areas indicate the [5\%, 95\%] confidence interval.

Figure 13. Impulse responses of country-specific risk factors to shocks of other countries 
Table 1. Summary of the convergence diagnostics for $A N^{4}(3,2,3)$ model

\begin{tabular}{cccccccc}
\hline \hline Model specification & Parameters & Under Q & $\sigma^{2}$ & $\mu$ & $\Phi$ & $\Omega$ & All \\
\hline \multirow{2}{*}{ Full $\Omega$} & Total number & 11 & 22 & 8 & 64 & 36 & 141 \\
& Convergence ratio & 0.82 & 1.00 & 1.00 & 1.00 & 1.00 & 0.99 \\
Diagonal $\Omega$ & Total number & 11 & 22 & 8 & 64 & 8 & 113 \\
& Convergence ratio & 1.00 & 1.00 & 1.00 & 1.00 & 1.00 & 1.00 \\
\hline \hline
\end{tabular}

Note: This table presents the convergence diagnostics results for the $A N^{4}(3,2,3)$ model. Total number is the total number of parameters for the model, while the next line below it reports the convergence ratio of the number of converged parameters versus the total number according to the CD test. The significance level used in the CD test is $10 \%$.

Table 2. Posterior BIC and BMT test results for $A N^{4}(3,2,3)$ and AFNS models

\begin{tabular}{llrrrr}
\hline \hline Test & & $A N^{4}(3,2,3)$ & $A F N S^{D E}$ & \multicolumn{1}{c}{$A F N S^{I T}$} & $A F N S^{E S}$ \\
\hline BIC & Full $\Omega$ & $-1.07 \mathrm{E}+08$ & $8.65 \mathrm{E}+04$ & $3.70 \mathrm{E}+04$ & $3.70 \mathrm{E}+04$ \\
& Diagonal $\Omega$ & $-3.58 \mathrm{E}+07 *$ & $8.80 \mathrm{E}+04 *$ & $3.75 \mathrm{E}+04 *$ & $3.74 \mathrm{E}+04 *$ \\
& & & & \\
BMT & J1 & $1.75 \mathrm{E}+12$ & 0.0 & 0.0 & 0.0 \\
& J0+J1 & $2.20 \mathrm{E}+18$ & 181.6 & 22.3 & 19.1 \\
& 48.3 & 11.3 & 11.3 & 11.3 \\
\hline \hline
\end{tabular}

Note: This table presents the Posterior BIC and BMT test results for specifications of $A N^{4}(3,2,3)$ and AFNS models. A star $(*)$ indicates that the model specification is favored by the test. 
Table 3. The VAR parameters under the risk-neutral measure

\begin{tabular}{lcccccccc}
\hline \hline$\mu^{Q}$ & $L$ & $S$ & $C$ & $L q$ & $C r$ & $F^{I T}$ & $F^{E S}$ & $F^{G R}$ \\
\hline & $6.4 \mathrm{E}-03^{* * *}$ & 0 & 0 & 0 & 0 & 0 & 0 & 0 \\
\hline$\Phi^{Q}$ & $L$ & $S$ & $C$ & $L q$ & $C r$ & $F^{I T}$ & $F^{E S}$ & $F^{G R}$ \\
\hline$L$ & 1 & 0 & 0 & 0 & 0 & 0 & 0 & 0 \\
$S$ & 0 & $0.990^{* * *}$ & $0.010^{* * *}$ & 0 & 0 & 0 & 0 & 0 \\
$C$ & 0 & 0 & $0.990^{* * *}$ & 0 & 0 & 0 & 0 & 0 \\
$L q$ & 0 & 0 & 0 & $0.998^{* * *}$ & 0 & 0 & 0 & 0 \\
$C r$ & 0 & 0 & 0 & 0 & $1.000 * * *$ & 0 & 0 & 0 \\
$F^{I T}$ & 0 & 0 & 0 & 0 & 0 & $0.997^{* * *}$ & 0 & 0 \\
$F^{E S}$ & 0 & 0 & 0 & 0 & 0 & 0 & $0.997 * * *$ & 0 \\
$F^{G R}$ & 0 & 0 & 0 & 0 & 0 & 0 & 0 & 1 \\
\hline \hline
\end{tabular}

Note: Since the retrieved yield data of Greece with maturities less than 10 years are constant after the European debt crisis, we only use data of Greece with maturity of 10 years and thus we have to set $\Phi^{G R^{\mathbb{Q}}}=1$ in order to specify the model. Asterisk $* * *$ indicates significance level of $1 \%$.

Table 4. Factor loadings of short rates on the market liquidity risk and common sovereign credit risk

\begin{tabular}{cccccc}
\hline \hline$b_{1}$ & & DE & IT & ES & GR \\
\hline \multirow{3}{*}{$b_{1}^{L q}$} & $5 \%$ quantile & 0 & 1.363 & 1.001 & 3.572 \\
& median & 0 & 1.524 & 1.002 & 5.223 \\
& $95 \%$ quantile & 0 & 1.673 & 1.003 & 7.396 \\
& & & & & \\
\multirow{2}{*}{$b_{1}^{C r}$} & $5 \%$ quantile & 0 & 0.458 & 0.477 & 1 \\
& median & 0 & 0.524 & 0.549 & 1 \\
& $95 \%$ quantile & 0 & 0.574 & 0.603 & 1 \\
\hline \hline
\end{tabular}

Note: $b_{1}^{C r}$ for Greece is set to 1 for identification. 
Table 5. VAR parameters under the physical measure

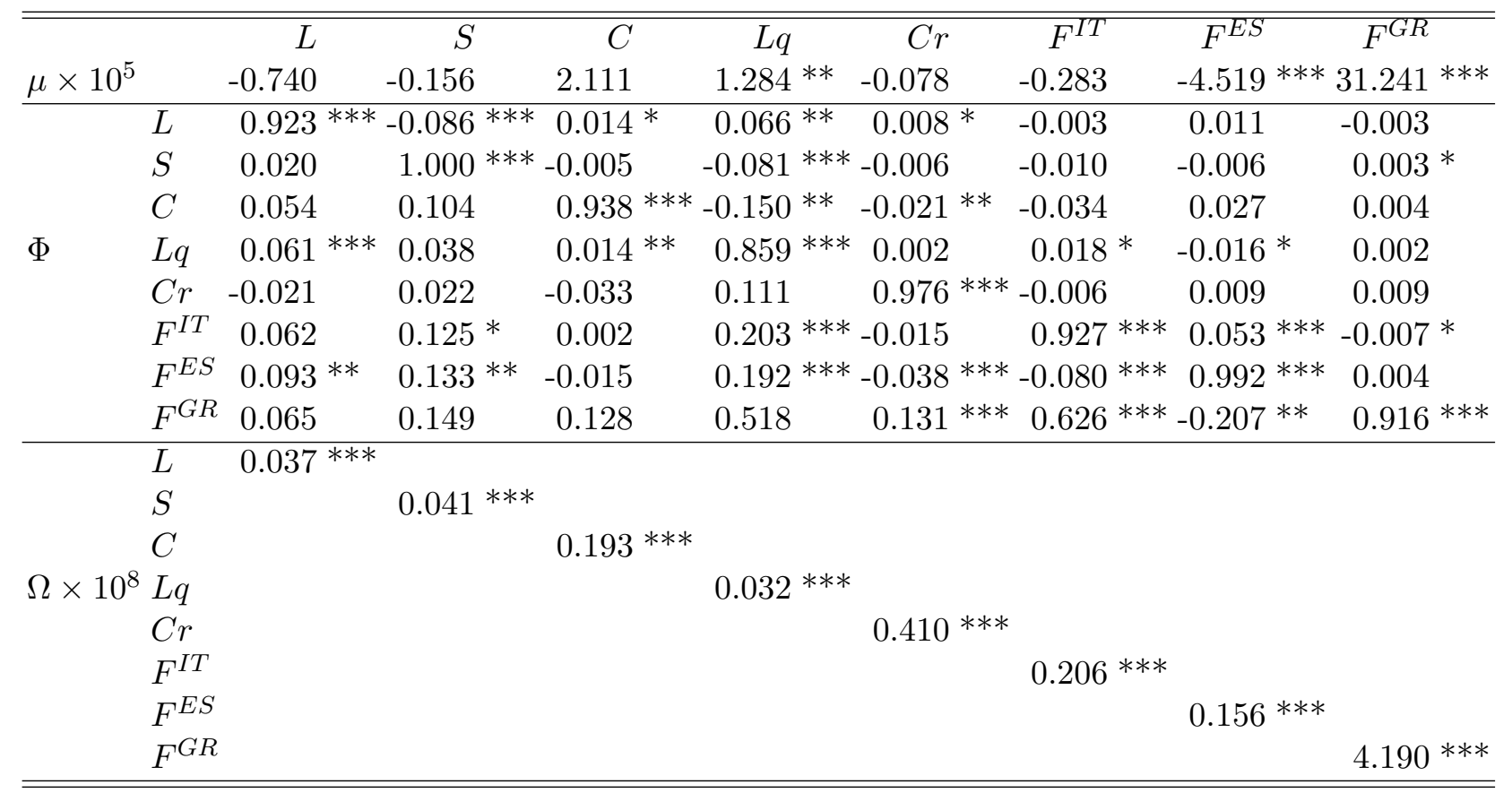

Note: Asterisk $*, * *$ and $* * *$ indicate significance levels of $10 \%, 5 \%$ and $1 \%$, respectively.

Table 6. Goodness of fit for $A N^{4}(3,2,3)$ model

\begin{tabular}{lccccccc}
\hline \hline Model & \# factor & \# parameter & & $D E$ & $I T$ & $E S$ & $G R$ \\
\hline$A N^{4}(3,2,3)$ & \multirow{2}{*}{113} & MAE & 3.49 & 7.66 & 10.92 & 20.13 \\
& & & RMSE & 4.39 & 9.58 & 13.54 & 45.05 \\
\multirow{2}{*}{$A F N S$} & \multirow{2}{*}{9} & \multirow{2}{*}{72} & MAE & 3.56 & 6.07 & 8.33 & - \\
& & & RMSE & 4.52 & 7.68 & 10.46 & - \\
\hline \hline
\end{tabular}

Note: The table compares the number of factors and parameters, and the average MAE and RMSE of yields of each country fitted by $A N^{4}(3,2,3)$ and AFNS models with diagonal $\Omega$ specification. Since only 10-year yield of Greece is available during the sample period, the AFNS model can not be applied to Greece. 